\title{
Overexpression of the MYB29 transcription factor affects aliphatic glucosinolate synthesis in Brassica oleracea
}

\author{
Diana L. Zuluaga ${ }^{1,7}$ (1) Neil S. Graham ${ }^{2} \cdot$ Annett Klinder $^{3}$. A. E. Elaine van Ommen Kloeke ${ }^{4}$ \\ Angelo R. Marcotrigiano ${ }^{5} \cdot$ Carol Wagstaff $^{3} \cdot$ Ruud Verkerk $^{6} \cdot$ Gabriella Sonnante $^{7} \cdot$ Mark G. M. Aarts $^{1}$
}

Received: 4 March 2019 / Accepted: 5 June 2019 / Published online: 12 June 2019

(c) The Author(s) 2019

\begin{abstract}
Key message Overexpression of BoMYB29 gene up-regulates the aliphatic glucosinolate pathway in Brassica oleracea plants increasing the production of the anti-cancer metabolite glucoraphanin, and the toxic and pungent sinigrin. Abstract Isothiocyanates, the bio-active hydrolysis products of glucosinolates, naturally produced by several Brassicaceae species, play an important role in human health and agriculture. This study aims at correlating the content of aliphatic glucosinolates to the expression of genes involved in their synthesis in Brassica oleracea, and perform functional analysis of BoMYB29 gene. To this purpose, three genotypes were used: a sprouting broccoli, a cabbage, and a wild genotype (Winspit), a high glucosinolate containing accession. Winspit showed the highest transcript level of BoMYB28, BoMYB29 and $B O A O P 2$ genes, and $B O A O P 2$ expression was positively correlated with that of the two $M Y B$ genes. Further analyses of the aliphatic glucosinolates also showed a positive correlation between the expression of $B O A O P 2$ and the production of sinigrin and gluconapin in Winspit. The Winspit BoMYB29 CDS was cloned and overexpressed in Winspit and in the DH AG1012 line. Overexpressing Winspit plants produced higher quantities of alkenyl glucosinolates, such as sinigrin. Conversely, the DH AG1012 transformants showed a higher production of methylsulphinylalkyl glucosinolates, including glucoraphanin, and, despite an up-regulation of the aliphatic glucosinolate genes, no increase in alkenyl glucosinolates. The latter may be explained by the absence of a functional AOP2 gene in DH AG1012. Nevertheless, an extract of DH AG1012 lines overexpressing BoMYB29 provided a chemoprotective effect on human colon cells. This work exemplifies how the genetic diversity of $B$. oleracea may be used by breeders to select for higher expression of transcription factors for glucosinolate biosynthesis to improve its natural, health-promoting properties.
\end{abstract}

Keywords MYB29 transcription factor · Brassicaceae plants · Glucosinolates · Isothiocyanates · Sinigrin · Antigenotoxic effect

\section{Introduction}

Brassica oleracea (CC genome) is a member of the Brassicaceae family and one of the three diploid Brassica species in the "triangle of $U$ " (Nagaharu 1935) that also includes the diploids $B$. rapa (AA) and B. nigra (BB) and the allotetraploids $B$. juncea (AABB), B. napus (AACC) and $B$. carinata (BBCC). Each of the Brassica genomes

Electronic supplementary material The online version of this article (https://doi.org/10.1007/s11103-019-00890-2) contains supplementary material, which is available to authorized users.

Diana L. Zuluaga

diana.zuluaga@ibbr.cnr.it

Extended author information available on the last page of the article has undergone a specific whole-genome triplication (Lysak et al. 2005). Brassica oleracea comprises many important vegetable crops including cauliflower, broccoli, cabbages, Brussels sprouts, kohlrabi and kales, which are high in carotenoids (Kopsell and Kopsell 2006) and contain diverse glucosinolates (GSLs), secondary metabolites, naturally produced by plants of the Brassicaceae family (Traka and Mithen 2009). A group of GSL products derived from enzymatic hydrolysis, isothiocyanates (ITCs), play important roles in human health and agriculture. Isothiocyanates are considered the main components responsible for the cancer-preventing properties of Brassica plants upon consumption by humans (Traka and Mithen 2009). For instance, sulforaphane, the aliphatic ITC generated from hydrolysis of 4-methylsulphinylbutyl 
GSL (glucoraphanin), exhibits chemopreventive properties, prohibiting the development of cancer cells via suppression of cytochrome P450 enzymes, induction of apoptotic pathways, inhibition of angiogenesis, antiinflammatory activity and suppression of cell cycle progression (Juge et al. 2007; Abdull Razis et al. 2017). Sulforaphane also activates the human Nrf2 transcription factor promoting the action of phase II detoxification enzymes, thus increasing cell defence against oxidative damage and enhancing the elimination of carcinogens (Chi et al. 2015; Su et al. 2018). Conversely, different types of ITCs, derived from aliphatic and aromatic GSLs, offer plant protection against several pathogens when used as a natural pesticide. For example, application of the aliphatic allyl ITC hydrolysis product of the 2-propenyl GSL (sinigrin) provides control of potato cyst nematodes (Pinto et al. 1998; Aires et al. 2009), soil-borne phytopathogenic fungi (Tiznado-Hernández and Troncoso-Rojas 2006), mealy cabbage aphid colonies (Newton et al. 2009), and beneficial soil invertebrates (Zuluaga et al. 2015). The natural toxic properties of ITCs make them useful as a more sustainable alternative to chemical fumigants in agricultural practices.

The aliphatic GSL biosynthetic pathway has been widely studied and described in Arabidopsis thaliana, including the identification of regulatory factors and structural genes involved in the process. Upon genome sequencing, putative orthologues of the A. thaliana genes have been found in $B$. rapa (Wang et al. 2011) and B. oleracea (Yi et al. 2015). For instance, BoGSL-ALK, the homolog of the A. thaliana AtAOP2 gene, encodes a 2-oxoglutarate-dependent dioxygenase, essential for the conversion of methylsulfinylalkyl GSLs to their alkenyl forms, therefore being one of the major genes controlling the glucoraphanin content in Brassica crops. In $B$. rapa all three $B r A O P 2$ paralogues are active but have functionally diverged, $B r A O P 2.1$ showed a slightly different pattern of expression in below-ground tissue at the seedling stage and in the silique at the reproductive stage compared with BrAOP2.2 and BrAOP2.3 genes (Zhang et al. 2015). Heterologous expression and in vitro enzyme assays and Arabidopsis mutant complementation studies showed that all three $B r A O P 2$ genes encode functional $B r A O P 2$ proteins that convert the precursor methylsulfinyl alkyl glucosinolate to the alkenyl form (Zhang et al. 2015). Brassica oleracea var. italica (broccoli) is known to contain a high concentration of glucoraphanin compared to other B. oleracea varieties, whereas sinigrin is only present in negligible concentrations, or even absent (Rangkadilok et al. 2002). Li and Quiros (2003) found that the accumulation of methylsulfinylalkyl GSLs in broccoli is linked to the presence of a non-functional allele of BoGSL-ALK in this crop. Therefore, the allelic variation for this $B O A O P 2$ homolog is a key element for defining the potential health promoting effect of
B. oleracea genotypes. The analysis of full-length cDNA libraries of kale, B. oleracea var. acephala, allowed to identify several genes related to the GSL biosynthetic pathway in this crop, including the transcription factor BoMYB29, the functional orthologue of the A. thaliana MYB29 gene controlling the expression of GSL biosynthesis genes (Araki et al. 2013).

The hypothesis behind this work is that BoMYB29 is one of the key transcription factors that controls expression of AGSL biosynthesis genes; upregulation of this transcription factor may be obtained through ectopic overexpression, which can increase the expression of AGSL biosynthesis genes and consequently the concentrations of one or several AGSL, including those that are human or plant health promoting. To verify this hypothesis, we correlated AGLS content to the expression of genes involved in the synthesis of these compounds in wild and cultivated B. oleracea genotypes, and performed a functional analysis of the BoMYB29 gene. Two genotypes showing a different AGLS profile were transformed with BoMYB29 driven by the CaMV $35 \mathrm{~S}$ promoter and transgenic plants were analysed for gene expression and AGLS production. The antigenotoxic activity of the BoMYB29 overexpressing plants was evaluated by assessing the potential of plant extracts to protect human colon cancer HT29 cells from DNA damage. The results obtained in this work provide useful information for breeding programmes focused on improving health-promoting properties of $B$. oleracea or anti-herbivore traits.

\section{Materials and methods}

\section{Plant material and growth conditions}

Brassica oleracea seeds from the genotypes listed below were sown in $17-\mathrm{cm}$ pots containing a peat-based commercial potting compost mixture (Lentse potgrond $\mathrm{nr} .4 ; 85 \%$ peat, $15 \%$ clay). Plants grew in a conditioned greenhouse set at a $8 \mathrm{~h} / 16 \mathrm{~h}$ dark/light photoperiod at $22{ }^{\circ} \mathrm{C}$.

For expression experiments and HPLC analysis on nontransgenic material, three $B$. oleracea genotypes were used: Winspit (WIN); the purple sprouting broccoli (B. oleracea var. italica Plenck) F1 hybrid cv. 'Santee' (PSB); and the Savoy cabbage (B. oleracea var. sabauda L.) F1 hybrid cv. 'Wintessa' (SAV). Winspit, a natural wild accession collected close to Winspit in the United Kingdom (Gols et al. 2008), was provided by Rieta Gols (Wageningen University, the Netherlands) and had proved to contain high levels of GSLs compared to other wild and cultivated $B$. oleracea plants (Gols et al. 2008; Harvey et al. 2011; Zuluaga et al. 2015). The purple sprouting broccoli cv. 'Santee' and the Savoy cabbage cv. 'Wintessa' were provided by companies as cultivars with high GSL levels. Since WIN seeds were 
collected in the field and are expected to be genetically heterogeneous, leaf material from four individual WIN plants (WIN5, WIN7, WIN9 and WIN14) was collected and analysed separately, with three technical replicates for each biological sample. For both PSB and SAV, 12 plants each were considered, divided in four groups of three plants each and analysed per group, since plants were assumed to be genetically homogeneous. Three mature, fully expanded, but not old, leaves were harvested per plant, after approximately 8 weeks, snap frozen in liquid nitrogen and stored at $-80^{\circ} \mathrm{C}$ until expression analysis was done.

For genetic transformation, Winspit and B. oleracea doubled haploid genotype DH AG1012 were used. DH AG1012 is derived from a cross between $B$. oleracea var. alboglabra (A12DHd) and B. oleracea var. italica (Green Duke GDDH33) (Sparrow et al. 2006). Seeds of DH AG1012 were provided by Penelope Sparrow (John Innes Centre, Norwich, UK).

\section{Cloning procedure and plasmid construction}

The coding sequence (CDS) of the B. oleracea MYB29 gene, paralogue 2 (BoMYB29) was isolated from the wild accession Winspit (Table S1). The BoMYB29 cDNA was amplified by reverse transcriptase (RT-)PCR using the primers BoMYB29_Gateway_F and BoMYB29_Gateway_R and WIN7 leaf cDNA as a template. The 954 bp BoMYB29-CDS (GenBank MK522798) PCR product was agarose-gel-purified (Qiagen, Crawley, UK) and cloned into the pENTR ${ }^{\mathrm{TM}}$ / D-TOPO Gateway donor vector (Invitrogen, http://www. invitrogen.com/) to create an entry clone. The insert was transferred from the entry clone into the pK7WG2D destination vector (VIB, Gent, Belgium) as described by the manufacturer (Invitrogen) to generate a 13,743-bp Pro35S::BoMYB29::Ter35S expression vector. This plasmid was transferred into Agrobacterium tumefaciens strain AGL1 (Lazo et al. 1991) by electroporation. This A. tumefaciens clone was used for DH AG1012 and Winspit transformation. AGL1 containing the pK7WG2D empty vector was used as a negative control for transformation (EV plants).

\section{Brassica oleracea transformation and regeneration}

Transformation of the DH AG1012 and Winspit genotypes was carried out following the method of Sparrow et al. (2006) with minor modifications. The AGL1 A. tumefaciens strain was grown on LB-agar medium containing $100 \mathrm{mg} / \mathrm{L}$ carbenicillin and $100 \mathrm{mg} / \mathrm{L}$ spectinomycin for selection and incubated at $28{ }^{\circ} \mathrm{C}$ for $48 \mathrm{~h}$. A single colony was transferred to $10 \mathrm{~mL}$ of $\mathrm{LB}$ medium containing the same selection antibiotics and grown while shaking at $28^{\circ} \mathrm{C}$ for $48 \mathrm{~h}$. A $50-\mu \mathrm{L}$ aliquot of the bacterial suspension was used to inoculate a 10-mL LB liquid culture, without antibiotics, which was grown overnight at $28{ }^{\circ} \mathrm{C}$ in a shaker. DH AG1012 and Winspit seeds were surface-sterilized by immersion in $100 \%$ ethanol for 2 min and subsequently in a 15\% (v/v) solution of sodium hypochlorite for $15 \mathrm{~min}$, upon which seeds were finally rinsed three times in sterile distilled water. The seeds were germinated on full-strength MS (Murashige and Skoog 1962) medium plus vitamins, supplemented with $3 \%$ sucrose and $0.8 \%$ Phytoblend (Caisson Laboratories, USA) at $\mathrm{pH}$ 5.7. Cotyledons were used for A. tumefaciens transformation. After $72 \mathrm{~h}$ in co-cultivation, the cotyledons were transferred to selection medium (co-cultivation medium supplemented with $160 \mathrm{mg} / \mathrm{L}$ Timentin and $15 \mathrm{mg} / \mathrm{L}$ kanamycin as the selective antibiotics). Regenerating $\mathrm{T}_{1}$ green shoots were excised and transferred to Gamborg's B5 medium consisting of Gamborg's B5 salts (Gamborg et al. 1968), plus 1\% sucrose, $0.8 \%$ Phytoblend, $160 \mathrm{mg} / \mathrm{L}$ Timentin and $25 \mathrm{mg} / \mathrm{L}$ kanamycin. After 3 weeks, $T_{1}$ shoots were transferred to pots with $50 \mathrm{~mL}$ of Gamborg's B5 medium with a higher concentration of kanamycin $(50 \mathrm{mg} / \mathrm{L})$. After transformants had developed a dense root system, $T_{1}$ plants (primary transgenic plants) were transferred to sterile peat in pots as described in the'Plant material and growth conditions' section. The transgenic nature of the plants was confirmed by a PCR analysis using the NPTII primers (Table S1). The expected sized fragment of $700 \mathrm{bp}$ was obtained for all transgenic lines and was not present in WT plants.

Six independent BoMYB29 $\mathrm{T}_{1}$ transgenic lines from DH AG1012 (DH1-DH6), and two primary $\mathrm{T}_{1}$ transgenic lines from Winspit (W1 and W2) were obtained. Transgene expression was analysed by qPCR in all the $\mathrm{T}_{1}$ lines and, as negative control, in three WT DH AG1012 and three Winspit plants. BoGAPDH was used as reference gene (Broekgaarden et al. 2008). $T_{2}$ seeds, obtained by self-crossing of $\mathrm{T}_{1}$ plants, were collected from $\mathrm{W} 1$ and $\mathrm{W} 2$ and from the three DH AG1012 lines with the highest expression of the transgene (DH3, DH5, DH6), surface-sterilized and then grown on Gamborg's B5 medium supplemented with $50 \mathrm{mg} / \mathrm{L}$ kanamycin. The germinated, kanamycin-resistant $\mathrm{T}_{2}$ transgenic seedlings were transplanted into soil. Six kanamycin-resistant $\mathrm{T}_{2}$ plants were selected per line (DH3, DH5, DH6, W1 and W2 lines), for transgene expression analysis (as described above). The three $\mathrm{T}_{2}$ transgenic plants of each line that showed the highest transgene expression values, were used for further expression and phenotypic analysis. Three mature fully expanded, but not old, leaves from three wild-type (WT) plants and three selected $\mathrm{T}_{2}$ transgenic plants from each BoMYB29 line, as well as empty vector plants (EV), were harvested after 8 weeks, stored at $-80{ }^{\circ} \mathrm{C}$ and used for expression or/and phenotypic analysis. 


\section{Microarray analysis}

The Affymetrix Brassica Exon 1.0 ST Array (Love et al. 2010) was used for gene expression analysis (microarray analysis). Hybridizations were carried out at the Nottingham Arabidopsis Stock Centre Affymetrix service (NASC, University of Nottingham, UK). Total RNA was obtained from the Winspit plants WIN5, WIN7, WIN9, WIN14, the PSB and SAV plant pools and the transgenic and wildtype DH AG1012 plants DH3, DH5, DH6, W1, W2, using the RNeasy Mini Kit (Qiagen). Total RNA samples were labelled, hybridised, and scanned following the standard protocol from the manufacturer (GeneChip Expression Analysis, Affymetrix, www.affymetrix.com). The GeneChip Command Console Software (AGCC; Affymetrix) was used to generate '.cel' files for each of the hybridisations. The raw chip data were normalised using the Robust Multichip Average (RMA) pre-normalisation algorithm (Irizarry et al. 2003) in the GeneSpring GX (version 11.5; Agilent Technologies) analysis software package. Following RMA pre-normalisation, the signals were further normalized by standardizing the signal value of each probe-set to the median of that probe-set across all hybridisations. All further analysis was carried out using different functions in GeneSpring GX software. Differentially expressed genes were identified when the WIN plants were analysed together using a two-step process; (i) an unpaired $T$ test using a Benjamini-Hochberg false discovery rate correction $(\mathrm{p}<0.05)$ and (ii) a fold-change $>1.5$ (Benjamini and Hochberg 1995). When the WIN plants were analysed separately, a probeset was identified to be differentially expressed if the foldchange was $>2$. Gene ontology (GO) analysis was performed using the GO analysis function in Genespring GX, with the p-value calculated using a hypergeometric test with Benjamini-Yekutieli correction (Benjamini and Yekutieli 2001). The GO analysis was performed on the A. thaliana paralogue of the Brassica gene, identified as the top hit from a BLAST (using NCBI BLASTn algorithm) analysis of the probe sequences against the $A$. thaliana genome.

\section{PCR and real-time quantitative PCR}

Real-time quantitative reverse transcriptase PCR (qRT-PCR) was used to investigate expression of selected $B$. oleracea AGSL biosynthetic genes. Gene expression was analysed using the SYBR Green dye and a CFX96 ${ }^{\mathrm{TM}}$ Real-Time PCR Detection System (Bio-Rad Laboratories, Richmond, CA). Expression levels were calculated relative to the expression of the BoGAPDH reference gene. The different isoforms/ paralogues of each $B$. oleracea GSL gene were distinguished using specific primers. Primers for gene expression analysis were designed based on $B$. oleracea sequences if available; otherwise, B. rapa sequences were used (Table S1). For DH
AG1012 BoGS-ALK (AOP2), PCR and sequencing were carried out with the odd 48 and odd 12 primers used by Gao et al. (2004) for broccoli.

Gene sequences were retrieved from the Brassica (BRAD; http://brassicadb.org/brad/) and GenBank (http:// www.ncbi.nlm.nih.gov/genbank/) databases. Most of the evaluated genes were chosen according to the gene inventory of the GSL pathway and B. rapa orthologues (Wang et al. 2011). Primers for expression analysis of BoGSLELONG, BoGSL-ELONG-L, BoGSL-PRO and BoGSL$P R O-L$ genes were designed based on literature information ( $\mathrm{Li}$ and Quiros 2002; Gao et al. 2006). Total RNA was isolated using the RNeasy Mini Kit (Qiagen) and reverse transcribed into cDNA, using the Script cDNA Synthesis Kit (Bio-Rad Laboratories, Richmond, CA, USA) according to the manufacturer's instructions. qRT-PCR experiments were carried out using $50 \mathrm{ng}$ of cDNA and the iQ SYBR Green Supermix (Bio-Rad) following the manufacturer's protocol. Relative quantification of each single gene expression was performed using the comparative $\mathrm{C}_{\mathrm{T}}$ method as described in the ABI PRISM 7700 Sequence Detection System User Bulletin \#2 (Applied Biosystems, Foster City, CA, USA). The relative expression levels were represented as heat maps, using BAR Heatmapper Plus software (http://bbc.botany.utoronto.ca/ntools/cgibin/ntools_heatmapper_plus.cgi). Correlation analysis between expression of AGSL pathway genes and AGSL content in the B. oleracea plants/genotypes was performed using the SPSS Statistics 17.0 Software (http://www.spss. com). Genes that were not expressed or expressed at very low levels were not included in the analysis. Pearson correlation analysis was performed between expression of AGSL genes and AGSL content in B. oleracea genotypes (Tables 1, S2a-d), and between expression of AGSL pathway genes and AGSL content in the B. oleracea WinMYB29 overexpressors (Tables 2, S2e, f). Correlation value was considered statistically significant at “*” $\mathrm{p}<0.05$ and “**" $\mathrm{p}<0.01$.

\section{Glucosinolate analysis}

The GSL extraction was performed according to Hennig et al. (2012) with slight modifications, using $200 \mathrm{mg}$ of fresh leaves in $1 \mathrm{~mL} 90 \%$ hot methanol, followed by one re-extraction in $1 \mathrm{~mL}$ of boiling $70 \%$ methanol. Extracts were subsequently analysed by means of high-performance liquid chromatography (HPLC) as described on a gradient system HPLC (Spectra Physics, San Jose, CA) using a Nova-Pak C18 column $(150 \mathrm{~mm})$ with a flow rate of $1 \mathrm{~mL} /$ min, injection volume of $20 \mu \mathrm{L}$ and column temperature of $20{ }^{\circ} \mathrm{C}$. Solvents and gradient were used as it was described by Hennig et al. (2012). GSL identification was based on 


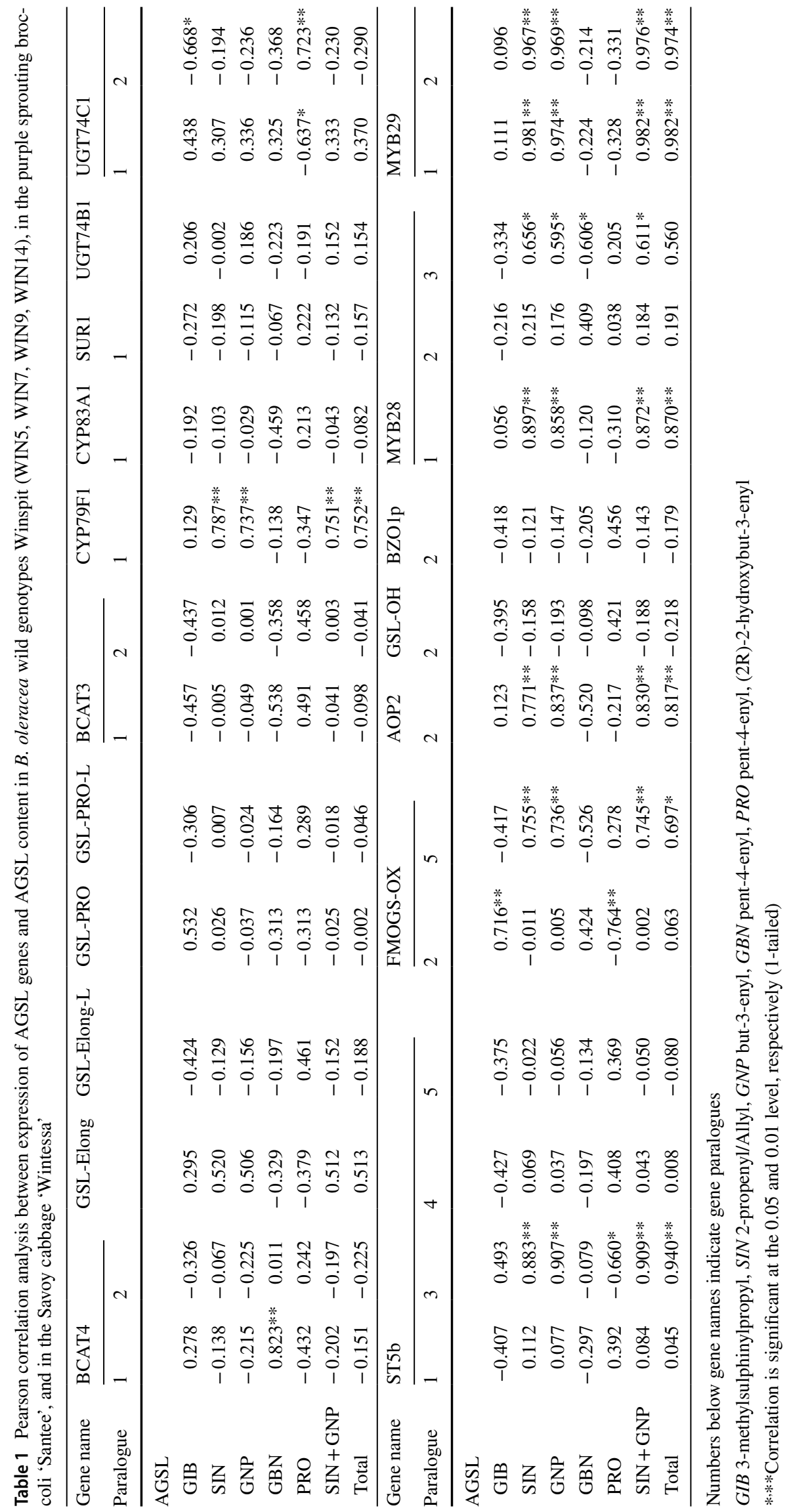




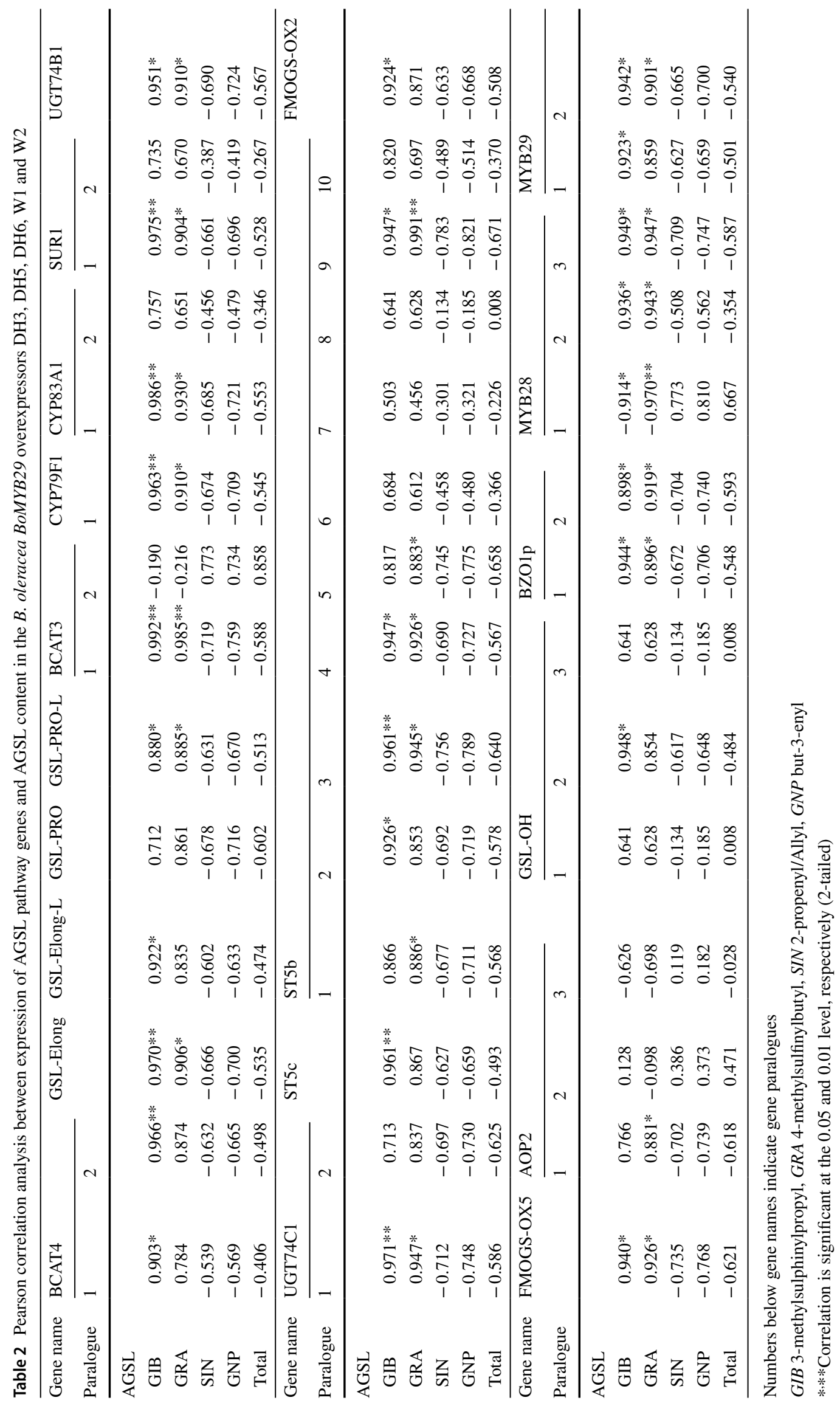


retention times compared to the internal standard glucotropaeolin or sinigrin: glucotropeolin $(25 \mu \mathrm{L}, 3 \mathrm{mM})$ as internal standard for WT and transgenic plant analysis, while sinigrin $(60 \mu \mathrm{L}, 3 \mathrm{mM})$ was the standard GSL for the extracts from the cell culture experiments. AGSL quantification was calculated using the internal reference and relative response factors (RRFs) in $\mu \mathrm{mol} / \mathrm{g}$ sample.

\section{Preparation of plant extracts and HT29 cell treatment}

GSLs from $200 \mathrm{mg}$ fresh weight (FW) of DH-WT1 and DH-TP6 plants were first extracted in $1 \mathrm{~mL}$ of boiling $90 \%$ methanol for $10 \mathrm{~min}$, keeping the samples in a water bath at $75^{\circ} \mathrm{C}$ and vortexing regularly. The supernatant was collected after centrifugation ( $5 \mathrm{~min}$ at $25,000 \times \mathrm{g}$ ), stored in ice and the pellet was re-extracted once more in the same way. Methanol was evaporated using a nitrogen evaporator (Tianjin Novelab Ltd., China). The dried content was diluted and took up to $1 \mathrm{~mL}$ serum-free Dulbecco's modified Eagle medium (DMEM; Sigma-Aldrich, Gillingham, UK) giving a stock solution of $200 \mathrm{mg} \mathrm{FW} / \mathrm{mL}$, which was frozen in aliquots of $200 \mu \mathrm{L}$ each until samples were added to the cells.

HT29 human colon cancer cells (Cohen et al. 1999) were cultured in DMEM, supplemented with $10 \%$ (v/v) fetal bovine serum and penicillin $(50 \mathrm{IU} / \mathrm{mL}) /$ streptomycin $(50 \mu \mathrm{g} / \mathrm{mL})$ in a humidified $5 \% \mathrm{CO}_{2}$ incubator at $37{ }^{\circ} \mathrm{C}$ and seeded at a concentration of $1 \times 10^{6}$ cells per well into 6-well culture dishes (CELLLSTAR ${ }^{\circledR} 6$ Well Cell Culture Multiwell Plates, Greiner Bio One) $24 \mathrm{~h}$ prior to incubation with the plant extracts. In order to test the chemoprotective potential on colon cancer cells, these were incubated with different concentrations of plant extracts for $24 \mathrm{~h}$. The plant extracts were derived from the wild type as well as from a $35 S:: B o M Y B 29$ transgenic plant corresponding to 10,100 and $1000 \mu \mathrm{g}$ of plant material (wet weight) per $\mathrm{mL}$ of cell culture medium, concentrations suggested by Gill et al. (2004) and Boyd et al. (2006). A control of incubated colon cancer cells grown in serum-free DMEM was run in parallel. After $24 \mathrm{~h}$, the incubated colon cells were harvested by trypsination, re-suspended in DMEM and centrifuged at $300 \times g$ for $8 \mathrm{~min}$ at RT. Subsequently, the cell pellet was resuspended in serum-free DMEM and cell number and viability of the treated cells were assessed by Trypan Blue assay. The cell concentration was adjusted to $1.5 \times 10^{6}$ cells $/ \mathrm{mL}$ and duplicated samples were either exposed to $75 \mu \mathrm{M} \mathrm{H}_{2} \mathrm{O}_{2}$ (induction of DNA damage) or serum-free DMEM (control) for $5 \mathrm{~min}$ on ice. The reaction was stopped by centrifuging cells at $280 \times g 5 \mathrm{~min}$ at $4{ }^{\circ} \mathrm{C}$ and washing the cell pellet once with serum-free DMEM. All cell culture reagents were provided by Lonza (Basel, Switzerland).

\section{Single cell gel electrophoresis: comet assay}

A 'Comet' assay was performed to measure the resulting DNA damage. Alkaline single cell gel electrophoresis was conducted as described by Singh et al. (1988). In brief, treated HT29 cells were centrifuged $\left(280 \times g 5 \mathrm{~min}\right.$ at $\left.4{ }^{\circ} \mathrm{C}\right)$ and the cell pellet was dissolved in low melting agarose before being transferred onto microscope slides. Slides were placed in lysis solution $\left(100 \mathrm{mM} \mathrm{Na} \mathrm{N}_{2}\right.$ EDTA, $1 \%$ Triton $\mathrm{X}$ $100,2.5 \mathrm{M} \mathrm{NaCl}, 10 \mathrm{mM}$ Tris, $\mathrm{pH} 10$ ) for $60 \mathrm{~min}$ at $4{ }^{\circ} \mathrm{C}$ and then transferred into the electrophoresis chamber containing ice-cold buffer ( $1 \mathrm{mM} \mathrm{Na} 2$ EDTA, $300 \mathrm{mM} \mathrm{NaOH}$, $\mathrm{pH} \geq 13$ ) and left for $20 \mathrm{~min}$ to allow the DNA to unwind. Afterwards, electrophoresis was performed for $20 \mathrm{~min}$ at $1.25 \mathrm{~V} / \mathrm{cm}$ and $300 \mathrm{~mA}$ at $4{ }^{\circ} \mathrm{C}$. Neutralisation buffer $(0.4 \mathrm{M}$ Tris, $\mathrm{pH}$ 7.5) was used to wash slides prior to staining with ethidium bromide (Sigma-Aldrich). Microscopic images of tail migration of DNA from the central cell mass were analysed using the Komet 5.5 software (Kinetic Imaging, Kinetic Imaging, Liverpool, UK), which calculated the proportion and extent of DNA migration. Fifty cells were analysed per slide. After incubation with the different plant extracts and concentrations, three independent experiments (one per sample) with three replicates each were performed. All the chemicals for single cell gel electrophoresis were purchased from Sigma-Aldrich.

The data from the present experiment were statistically evaluated using ANOVA for repeated measures with Tukey's post hoc test.

\section{Data availability}

All data generated from the Affymetrix Brassica Exon 1.0 ST Array analysis have been deposited in the NCBI Gene Expression Omnibus (Edgar et al. 2002) and are accessible through GEO Series, accession number GSE39951 (http:// www.ncbi.nlm.nih.gov/geo/query/acc.cgi?acc=GSE39951).

\section{Results}

\section{Aliphatic glucosinolate production in B. oleracea genotypes correlates with the expression of glucosinolate biosynthesis genes}

In order to evaluate whether the content of AGSLs in the different genotypes analysed was correlated to gene expression, the four Winspit plants plus the PSB and SAV cultivars were used to perform HPLC analyses, microarray and qRTPCR transcription profiling assays. Profiles and quantities of AGSLs differed between leaves of Winspit and the cultivated PSB and SAV lines. Although variation was observed among Winspit individuals, in general the wild genotypes 
Fig. 1 Heatmap of gene expression related to aliphatic glucosinolate (AGSL) biosynthesis and AGSL concentrations in leaves of $B$. oleracea wild accession Winspit (WIN), purple sprouting broccoli 'Santee' (PSB) and 'Wintessa' Savoy cabbage (SAV). Real-time quantitative qPCR analyses of the AGSL biosynthesis genes in four WIN plants (WIN5, 7, 9 and 14) and the F1 hybrid cultivars PSB and SAV (a). Expression levels are normalized to the expression of reference gene $B o G A P D H$. Aliphatic GSL concentrations in the same material (b). The boxed heatmap legend corresponds to gene expression, the boxless legend corresponds to the GSL concentrations. On the right side of the figure, the aliphatic GSL pathway is displayed and genes are arranged according to their role in the pathway. Full gene names and primers are listed in Supplemental Table S1. NE not expressed, GSL glucosinolate, $F W$ fresh weight

\section{B. oleracea genotypes}

\begin{tabular}{llllll} 
WIN 5 & WIN7 & WIN9 & WIN 14 & PSB & SAV \\
\hline
\end{tabular}

(A)

3-Methylsulphinylpropyl (GIB)

4-Methylsulphinylbutyl (GRA)

2-propenyl/Allyl (SIN)

But-3-enyl (GNP)

Pent-4-enyl (GBN)

(2R)-2-Hydroxybut-3-enyl (PRO)

Total

(B)

Gene name

BoBCAT4 (1)

BOBCAT4 (2)

BoGSL-ELONG

BOGSL-ELONG-L

BOGSL-PRO

BOGSL-PRO-L

BOBCAT3 (1)

BOBCAT3 (2)

BoCYP79F1 (1)

BoCYP83A1 (1)

BoCYP83A1 (2)

BOSUR1 (1)

BOSUR1 (2)

BoUGT74B1

BoUGT74C1 (1)

BoUGT74C1 (2)

BoST5C

BOST5b (1)

BoST5b (2)

BoST5b (3)

BoST5b (4)

BoST5b (5)

BoST5b (6)

BoST5b (7)

BoST5b (8)

BoST5b (9)

BoST5b (10)

BOFMOGS-OX2

BOFMOGS-OX5

BoAOP2 (1)

BOAOP2 (2)

BOAOP2 (3)

BOGSL-OH (1)

BoGSL-OH (2)

BoGSL-OH (3)

BoBZO1p (1)

BoBZO1p (2)

BoMYB28 (1)

BoMYB28 (2)

BoMYB28 (3)

BoMYB29 (1)

BOMYB29 (2)
AGSL content ( $\mu \mathrm{mol} / \mathrm{g} \mathrm{FW})$

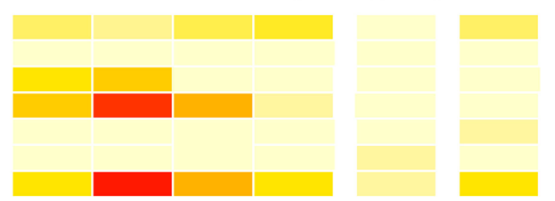

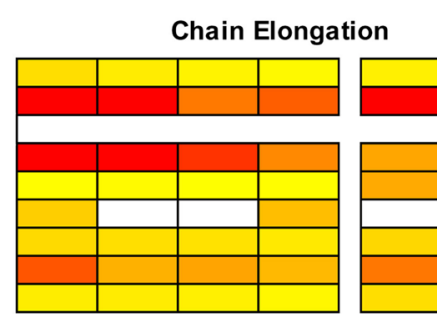

GSL Biosynthesis
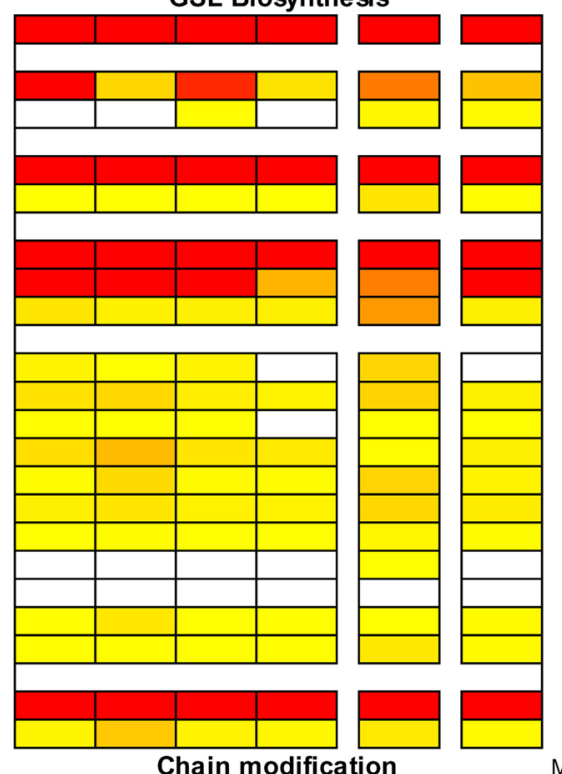

Chain modification
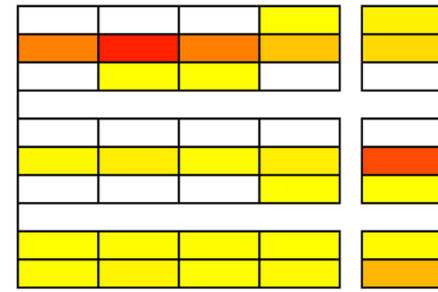

Transcription factors
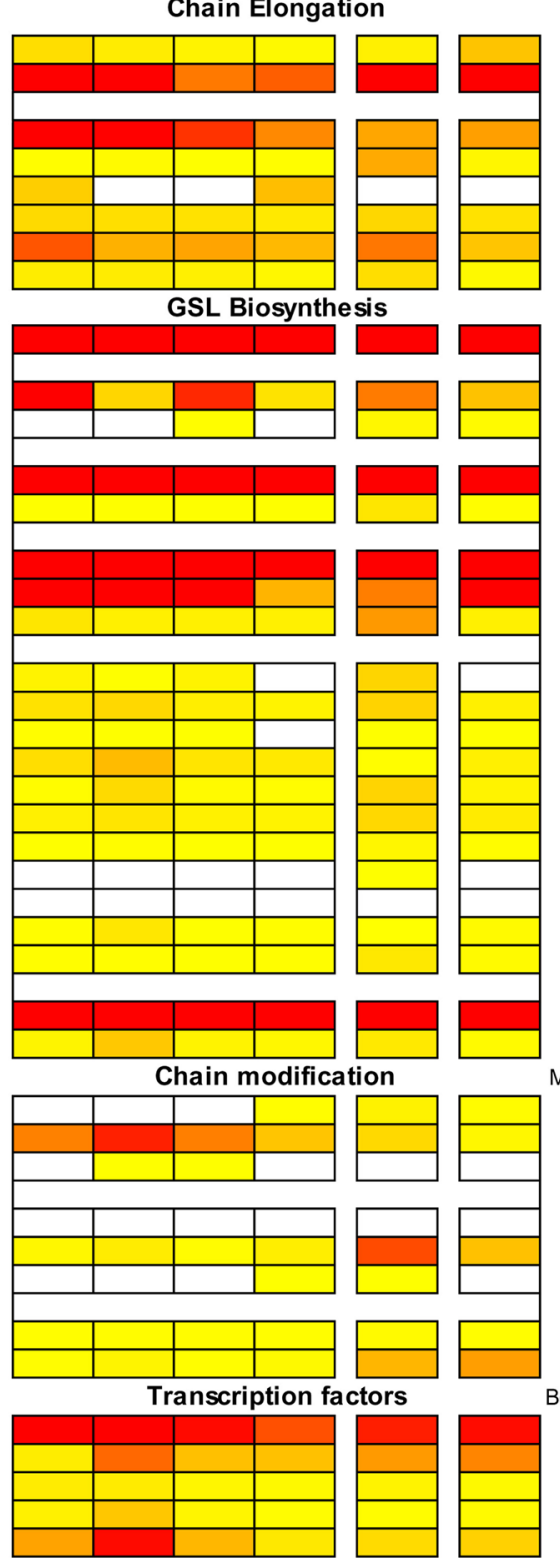

Chain elongated methionine

$\downarrow$

Aldoxime

$\downarrow$

S-alkyl-thiohydroximate

$\downarrow$

Thiohydroximic acid

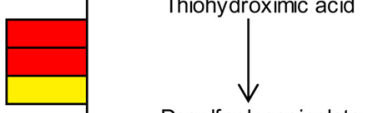

Desulfoglucosinolate

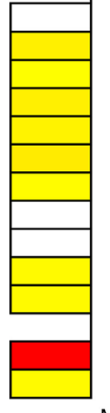

Methysulfinylalkyl-GSL (GIB/GRA)

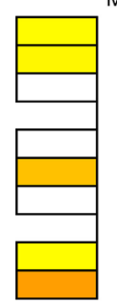

$\downarrow$

Alkenyl-GSL (SIN/GNP/GBN)
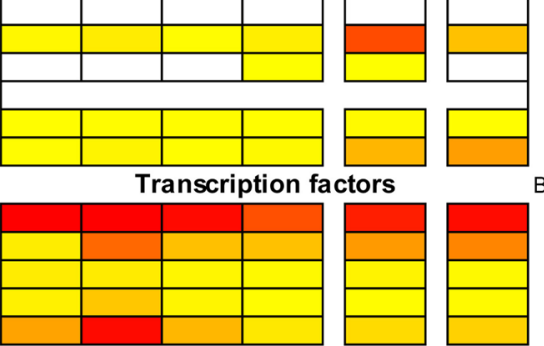

Benzoyloxyalkyl-GSL

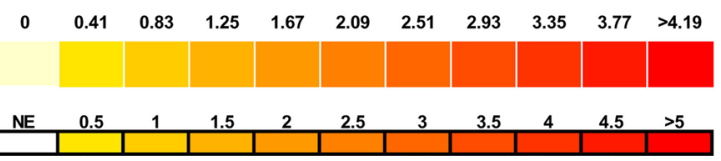


displayed a higher AGSL concentration compared to the two crops, particularly for the alkenyl-GSLs gluconapin (GNP) and sinigrin (SIN) (Fig. 1a, Table S3). In particular, WIN7 showed the highest concentration of GNP and SIN compared to all other genotypes. The striking differences in GSL levels among the examined plant material might be due to differences in either expression or function of genes involved in GSL biosynthesis. To determine gene expression, leaf material of all genotypes was used for Affymetrix Brassica Exon 1.0 ST microarray hybridisation. The results of the microarray assay were used to perform a Principle Component Analysis (PCA) (Fig. S1), showing that the three B. oleracea types differed from each other with respect to overall gene expression. As expected, WIN plants were more heterogeneous than both the F1 hybrid cultivars and, on the whole, more similar to SAV than to PSB plants. When the combined WIN expression data were compared to the two cultivars, 656 probe sets were significantly differentially expressed between WIN and PSB and 699 probe sets between WIN and SAV. In total, 170 probe sets were significantly differentially expressed between WIN and both PSB and SAV (Table S4). Gene Ontology analysis of these differentially expressed genes revealed that GO terms related to 'mucilage metabolism and extrusion', 'seed coat development' and 'seedling development' were significantly overrepresented in the WIN genotypes (Table S5).

In order to specifically analyse genes of the GLS pathways, a panel of 216 probe sets, representing genes that were previously considered to be relevant for GSL biosynthesis (Wang et al. 2011), was examined for differential expression between WIN plants and the two cultivars (Fig. S2). Four GSL genes were significantly differentially expressed between WIN and PSB: BoGSL-OH (Bra021670, predicted to encode a 2-oxoacid dependent dioxygenase) and BoIPMI SSU2 (Bra004744, predicted to encode an isopropylmalate dehydratase) were both down-regulated in WIN, while BoGSTF9 (Bra022815, predicted to encode glutathione S-transferase phi9) and BoST5a (Bra008132, predicted to encode desulfoglucosinolate sulfotransferase 5a) were both up-regulated in WIN. The same genes, except for BoGSTF9, were differentially expressed between WIN and SAV.

The number of genes differentially expressed between each Winspit line and the cultivars varies. Three probe sets (rres089630.v1_st, Bra023450; rres017223.v1_st, Bra021670; rres045980.v1_x_st, Bra021670) were found to be consistently differentially expressed between WIN7 and the other genotypes. Of these genes, Bra023450 was up-regulated (3.5 vs. SAV, 5.2 vs. PSB), while Bra021670 was down-regulated. Similar results were obtained for WIN5 (three probe sets) and WIN9 (five probe sets). Of these probe sets, two were consistently differentially expressed in all WIN lines compared to the cultivated plants: Bra023450 (rres089630.v1_st) encoding a 3-methyladenine DNA glycosylase and Bra021670 (rres017223.v1_st) encoding a putative dioxygenase, were up-regulated and down-regulated in WIN, respectively.

To complement the microarray analysis and to study the B. oleracea AGSL pathway in more detail, expression of different AGSL genes identified in B. rapa and B. oleracea (Li and Quiros 2002; Gao et al. 2006; Wang et al. 2011) was determined by qRT-PCR analysis. In addition, expression of the different paralogues of those genes, which may not have been distinguished by microarray analysis, was assessed. Altogether, the expression of 42 AGSL biosynthesis pathway genes was assessed (Fig. 1b). The difference in AGSL production in the B. oleracea genotypes used in this study showed a positive correlation with the expression of BoMYB29 and BoMYB28 transcription factor genes and BoBCAT4(1), BoGSL-PRO, BoCYP79F1, BoSUR1, $B o S T 5 b(3), B o F M O G S-O X(5)$ and BoAOP2(2) structural genes (Table 1). The high AGSL containing genotype, WIN7 showed the highest relative expression of these genes. In contrast, both cultivars and WIN14, which displayed low AGSL production, also showed low expression of the abovementioned genes.

\section{MYB29 from Winspit regulates the expression of several genes in B. oleracea}

Although the AGSL concentrations in the WIN genotypes were naturally high, we wanted to investigate if overexpression of one of the transcriptional regulators of the AGSL pathway could increase the AGSL leaf content to even higher levels. Among the key regulators whose expression was positively and significantly correlated with AGSL content, we chose BoMYB29(2) since its expression in the different genotypes used in this study showed the same trend as the expression of BoAOP2 (Fig. 1), a gene crucial for the synthesis of Alkenyl-GSL. Therefore, we cloned the WIN7 MYB29(2) gene (BoMYB29) by RT-PCR from RNA and constructed an A. tumefaciens vector under the control of the constitutive CaMV 35S promoter. The DH AG1012 genotype, which can be easily transformed (Sparrow et al. 2006), and plants of the wild $B$. oleracea accession Winspit, were genetically modified using the Pro35S::BoMYB29 construct. Six and two independent transformants were obtained from DH AG1012 and from Winspit, respectively. Preliminary phenotypic data did not show any difference in AGSL type and concentration between WT and EV plants. Therefore, WT plants growing at the same environmental conditions as the BoMYB29 transgenic lines were used as a control of the transformation.

In order to evaluate the effect of BoMYB29(2) overexpression, we used the same Affymetrix Brassica Exon 1.0 ST microarray as above. The expression levels of GSL biosynthesis related genes, consisting of 216 probe sets, 
representing 86 Brassica genes (Wang et al. 2011), were assessed in the transformed DH and Winspit lines and compared to the WT plants. A profile plot and a hierarchical clustering showed that many GSL related genes are up-regulated and several other genes down-regulated in the $\mathrm{DH}$ BoMYB29-overexpressing lines, compared to the control plants (Fig. S3a, b). Out of the 216 GSL related probe sets, a group of 46, representing 24 genes, was consistently up-regulated in the transgenic lines DH3, DH5 and DH6 (Fig. S3b; Tables S6, S7). The same analysis was performed for the two transgenic Winspit lines, compared to the control plants. Hierarchical clustering analysis of the Winspit BoMYB29overexpressing lines demonstrated that a smaller number of genes was up-regulated as compared to the DH BoMYB29 transgenic lines (Fig. S3c; Table S8). Only eleven probe sets (representing nine genes) were differentially expressed in $\mathrm{W} 1$, twenty probe sets in W2 (representing 16 genes), and eight probe sets (representing seven genes) were consistently differentially expressed in the two Winspit transgenic lines compared to the wild type.

Quantitative qRT-PCR experiments were performed to confirm the microarray data. Expression of the 42 AGSL genes analysed previously was studied for the BoMYB29 transgenic lines and their respective WT backgrounds. BoMYB29 was highly up-regulated in all transformants, especially in the DH lines (Fig. 2a). For the DH AG1012 BoMYB29 overexpression lines, at least one paralogue of each of the 42 genes analysed was up-regulated in the transgenics compared to the WT, while BoST5b (gene 5) and BoMYB28 (genes 1 and 2) were the only genes that did not display an up-regulation in the transgenic lines. BoBCAT4 (genes 1 and 2), BoGSL-ELONG and BoST5c were highly up-regulated (Fig. 2a). Other genes with $>20$-fold up-regulation in DH AG1012 transgenic lines were BoCYP79F1(1), BoCYP83Al(2), BoSURl(1), BoUGT74Cl(1), BoST5B(1), BoFMOGS-OX2, BoGSL-OH(2), BoBZOlp(2). Winspit overexpressing lines displayed less activity of the transgene compared to the DH tranformants. In fact, in the Winspit transgenic plants just a few GSL genes displayed an upregulation due to the overexpression of MYB29. Among the genes highly expressed in the Winspit overexpressing lines are BoBCAT4(1), BoBCAT3(2) and BoSURl(2) with more than two times up-regulation in $\mathrm{W} 1$ compared to the respective WT. In general, BoBCAT4 and BoBAT5, encoding the sodium symporter protein 5 , were the strongest expressed genes among the up-regulated ones in the overexpressing lines.

\section{BoMYB29 overexpression increases the AGSL production in B. oleracea plants}

The overexpression of BoMYB29 did not only induce the overexpression of several GSL related genes, but also led to
(A)

Gene name

BoBCAT4 (1)

BOBCAT4 (2)

BOGSL-ELONG

BOGSL-ELONG-L

BOGSL-PRO

BoGSL-PRO-L

BoBCAT3 (1)

BoBCAT3 (2)

BoCYP79F1 (1)

BoCYP83A1 (1)

BoCYP83A1 (2)

BOSUR1 (1)

BOSUR1 (2)

BoUG T74B1

BoUGT74C1 (1)

BoUGT74C1 (2)

BoST5c

BoST5b (1)

BoST5b (2)

BoST5b (3)

BoST5b (4)

BoST5b (5)

BoST5b (6)

BoST5b (7)

BoST5b (8)

BoST5b (9)

BoST5b (10)

BoFMOGS-OX2 BOFMOGS-OX5

BOAOP2 (1)

BOAOP2 (2)

$B O A O P 2$ (3)

BoGSL-OH (1)

BoGSL-OH (2)

BoGSL-OH (3)

BoBZO1p (1)

BoBZO1p (2)

BoMYB28 (1)

BoMYB28 (2)

BoMYB28 (3)

BoMYB29 (1)

BoMYB29 (2)

(B)

3-Methylsulphinylpropyl (GIB)

4-Methylsulphinylbutyl (GRA)

2-propenyl/Allyl (SIN)

But-3-enyl (GNP)

Total

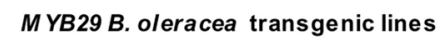

\begin{tabular}{lllll}
$\mathrm{DH} 3$ & $\mathrm{DH} 5$ & $\mathrm{DH} 6$ & $\mathrm{~W} 1$ & $\mathrm{~W} 2$ \\
\hline
\end{tabular}

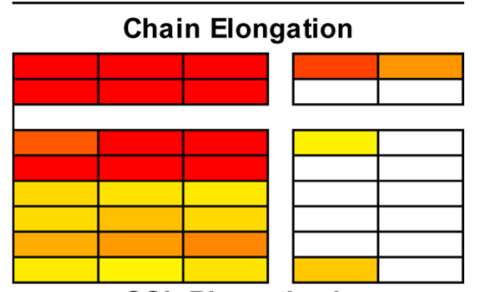

GSL Biosynthesis
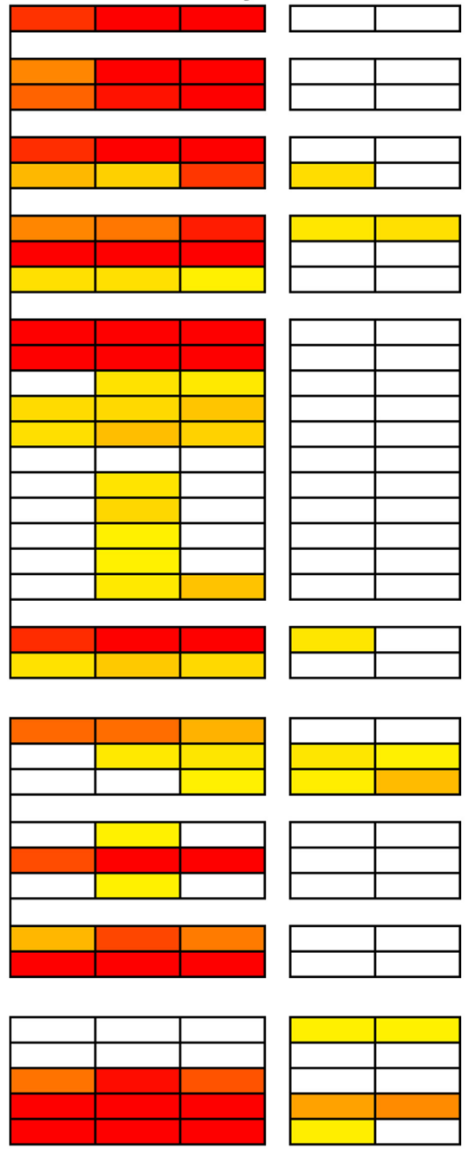

AGSLs content ( $\mu \mathrm{mol} / \mathrm{g} \mathrm{FW})$

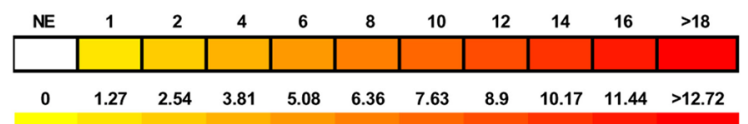

Fig. 2 AGSL gene expression level and AGSL concentration in the MYB29 overexpressing lines. Relative expression level of the 42 AGSL related genes in the MYB29 DH AG1012 transgenic DH3, DH5 and DH6 lines compared to the wild type DH-WT1, and the MYB29 Winspit overexpressing W1 and W2 lines compare to the wild-type W-WT1 (a). AGSL content in the MYB29 overexpressing DH3, DH5, DH6 and W1, W2 lines compare to wild-type DH-WT1, W-WT2 plants respectively (b). Colours indicate expression level compared to BoGAPDH housekeeping gene expression. $N E$ not expressed gene, $G S L$ glucosinolate, $F W$ fresh weight 
higher levels of AGSLs in the transgenic $B$. oleracea plants, when compared to their WT control plants (Figs. 2b, S4; Table S3). As for the DH AG1012 BoMYB29 transgenics, a higher production of methylsulphinylalkyl-GSLs compared to the WT plants was observed. The expression of several genes showed a significant correlation $(\mathrm{p}<0.01)$ with the production of methylsulphinylalkyl-GSLs (Table 2). For instance, the expression of BoBCAT4(2), BoGSL-Elong, BoSURl(1), BoUGT74B1, BoUGT74Cl(1) and BoST5c genes was significantly correlated with the production of glucoraphanin in the overexpressing plants, while the expression of BoBCAT3(1), BoCYP83Al(2), BoST5b(3) was correlated with both glucoraphanin and glucoiberin production.

On the other hand, in the BoMYB29 overexpressing Winspit lines, high levels of alkenyl-GSLs were found, while no methylsulphinylalkyl-GSLs could be detected, suggesting that all the methylsulphinylalkyl-GSLs were converted into alkenyl-GSLs (Fig. 2b). The two Winspit overexpressing lines contained significantly more 2-propenyl/allyl (sinigrin) and butenyl GSL (gluconapin), as well as total AGSL levels, than their control. The total GSL content was positively and significantly correlated with the expression of the $B o B$ CAT3(2) gene in Winspit transgenic lines (Table 2). Conversely, DH AG1012 plants produced methylsulphinylalkylGSLs and no alkenyl-GSL form (Fig. S4). Amplification and sequencing of the DH AG1012 BoGS-ALK (BoAOP2) gene, encoding the 2-oxoglutarate-dependent dioxygenase involved in this biochemical conversion, showed the presence of a 2-bp deletion in exon 2 of BoAOP2 paralogues, as it was previously shown by Gao et al. (2004) in broccoli.

\section{DH6 GSL extract produces a protective effect against $\mathrm{H}_{2} \mathrm{O}_{2}$-induced DNA damage}

The chemopreventive properties of B. oleracea plant extracts were tested by assessing their potential to protect human colon HT29 cells from DNA damage by hydrogen peroxide, a proven genotoxic compound. For this assay, we used the wild type DH-WT1 and the transgenic line DH6, showing the highest GSL content among the obtained transformants. The Comet assay (single-cell gel electrophoresis) is a simple method for measuring DNA strand breaks in eukaryotic cells (Collins 2004). Comet assay experiments performed without addition of hydrogen peroxide showed that the plant extracts did not induce DNA damage themselves as there was no difference in baseline DNA damage after $24 \mathrm{~h}$ incubation with plant extracts compared to incubation with serum-free medium (control) (Repeated Measures ANOVA with Tukey's post hoc test, $p=0.074$ ) (Fig. 3). Incubating the control sample with hydrogen peroxide led to the induction of considerable DNA damage (Tail fluorescence intensity: $19.2 \pm 4.1 \%$ mean \pm SD Tail DNA) (Fig. 3). Analysis

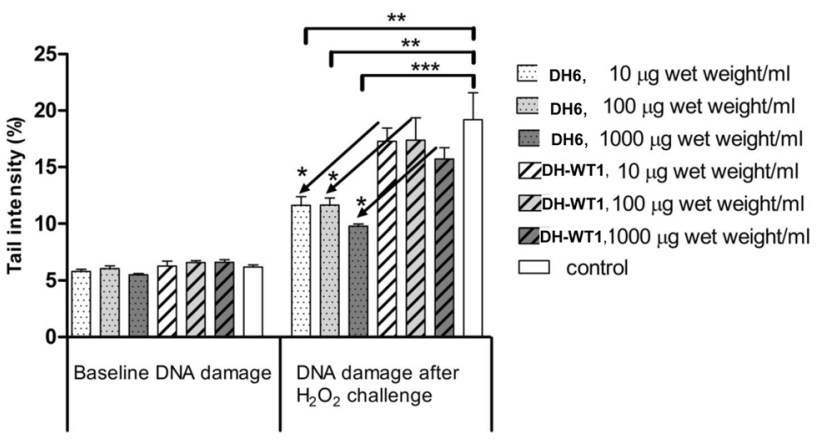

Fig. 3 Chemopreventive effect of GSL-rich extract from DH AG1012 BoMYB29 transgenic plant leaves against $\mathrm{H}_{2} \mathrm{O}_{2}$ induced DNA damage. Comparison of the plant extracts against untreated control (white bars) without $\mathrm{H}_{2} \mathrm{O}_{2}$ (baseline DNA damage) and with $\mathrm{H}_{2} \mathrm{O}_{2}$ (DNA damage after $\mathrm{H}_{2} \mathrm{O}_{2}$ challenge). Comparison between DH6 plant treatments and DH-WT1 plant treatments: DH6, 1000 versus DH-WT1, 1000; DH6, 100 versus DH-WT1, 100; and DH6, 10 versus DH-WT1, 10, without $\mathrm{H}_{2} \mathrm{O}_{2}$ (left part) and with $\mathrm{H}_{2} \mathrm{O}_{2}$ (right part). DH6: DH AG1012 transgenic line 6; DH-WT1: DH AG1012 wild type. ${ }^{*} \mathrm{p}<0.05 ; * * \mathrm{p}<0.01 ; * * * \mathrm{p}<0.001$ (ANOVA for repeated measures with Tukey's post hoc test)

with Repeated Measures ANOVA revealed that results for hydrogen peroxide induced DNA damage differed significantly according to treatment $(\mathrm{p}=0.0002)$. Tukey's post hoc test showed that while incubation for $24 \mathrm{~h}$ with wildtype extracts had no effect on DNA strand breaks induced by hydrogen peroxide, incubation with DH6 and DH-WT1 GSL extracts significantly reduced DNA damage compared to the control sample $(\mathrm{p}<0.01, \mathrm{p}<0.01$ and $\mathrm{p}<0.001$ for $10 \mu \mathrm{g} / \mathrm{mL}, 100 \mu \mathrm{g} / \mathrm{mL}$ and $1000 \mu \mathrm{g} / \mathrm{mL}$ fresh weight of transgenic plant extracts compared to serum-free medium, respectively). Extracts from the DH6 transgenic line were also significantly more effective in preventing DNA strand breaks than the DH-WT1 extracts at the respective concentrations ( $<<0.05$ for $10 \mu \mathrm{g} / \mathrm{mL}$ DH6 vs. DH-WT1, $100 \mu \mathrm{g} /$ mL DH6 vs. DH-WT1 and $1000 \mu \mathrm{g} / \mathrm{mL}$ DH6 vs. DH-WT1).

\section{Discussion}

The focus of this study was to analyse the expression of the genes involved in the AGSL biosynthesis in B. oleracea, and establish a correlation between AGSL production and gene expression in WIN plants, and PSB and SAV varieties.

The AGSL pathway is well known in B. rapa, where a comprehensive map of the involved genes has been created (Zang et al. 2009; Wang et al. 2011). Moreover, B. oleracea genome is already available (Liu et al. 2014), showing a genetic similarity with the $B$. rapa genome and some knowledge regarding the $B$. oleracea AGSL pathway has been also achieved (Yi et al. 2015). In this study, the expression of most of the B. oleracea genes homologous to the 
previously identified $B$. rapa genes was assessed. However, for the BoST5b and $\mathrm{BoGSL}-\mathrm{OH}$ genes, one paralogue identified in $B$. rapa was not found in B. oleracea. Our microarray data showed also that BoGSL-OH, a 2-oxoacid-dependent dioxygenase, is down-regulated in WIN compared to the cultivated genotypes. The gene encoding $B o G S L-O H$ is necessary for the synthesis of the (2R)-2 Hydroxybut-3-enyl-GSL (progoitrin) from But-3-enyl GSL (gluconapin). Therefore, this could be the main reason why the alkenyl-GSLs, in particular sinigrin and gluconapin, are predominant in the wild genotype.

Moreover, our study showed a significant positive correlation between the relative expression levels of the BoMYB28 and BoMYB29 transcription factor genes with the AGSL content. Additionally, several structural genes were also positively correlated with AGSL production. It is therefore highly likely that expression of the BoBCAT4, BoGSL-PRO, BoCYP79F1, BoSUR1, BoST5b, BoFMOGS$O X 5$ and BoAOP2 genes is controlled by the BoMYB28 and/or BoMYB29 transcription factors. Moreover, the high, positive correlation between the expression of the two $M Y B$ genes and BoAOP2 with the concentration of 2-propenyl (sinigrin) and but-3-enyl (gluconapin) AGSLs highlights the important role of BoMYB29 and BoMYB28 in the regulation of $B o A O P 2$ and the synthesis of alkenyl-GSLs in B. oleracea. Such control of AGSL biosynthesis gene expression is in agreement with what has been found for A. thaliana, where AtMYB28 and AtMYB29 also regulate the expression of AtAOP2, among other genes (Sønderby et al. 2007; Hirai et al. 2007). Additionally, AtAOP2 is responsible for the conversion of the methylsulfinylalkyl-GSLs into the alkenyl form, which is essential for the production of alkenyl-GSLs (Neal et al. 2010). On the other hand, expression of Brassica $A O P 2$ genes has been studied before, for both $B$. rapa (Wang et al. 2011; Zhang et al. 2015) and B. oleracea (Gao et al. 2004; Li et al. 2014), as well as one of its regulatory genes, $M Y B 28$, which in $B$. rapa has been identified as negative regulator of BrAOP2 (Seo et al. 2016). In this work, expression analysis of GSL genes in $B$. oleracea plants showed a positive correlation between BoMYB29 and BoAOP 2 gene expression, especially with the $B o A O P 2(2)$.

Since the expression of BoMYB29 was positively correlated with that of $B O A O P 2$, we performed functional analysis of MYB29 in two B. oleracea genotypes (Winspit and DH AG1012) with different GSL profiles, and analysed the effects of overexpression of the MYB29 gene, at the transcriptional and phenotypic level. In the model species $A$. thaliana, closely related to $B$. oleracea, knockout mutant and ectopic expression studies have demonstrated the positive regulation that $M Y B 28$ and MYB29 transcription factors play in the AGSL pathway (Hirai et al. 2007; Beekwilder et al. 2008; Gigolashvili et al. 2008; Yin et al. 2017). However, while $M Y B 28$ has been identified as the dominant regulator,
MYB29 is suggested to have a minor rheostat role in constitutive glucosinolates biosynthesis in Brassica (Gigolashvili et al. 2007; Hirai et al. 2007; Sønderby et al. 2007, 2010). Other studies found an important activation role of AtMYB29 for the AGSL biosynthesis and suggested that AtMYB29 contributes equally together with $A t M Y B 28$ to regulate the AGSL biosynthesis in A. thaliana (Beekwilder et al. 2008). Furthermore, when a $B$. oleracea BoMYB29 gene isolated from kale (B. oleracea var. acephala) was overexpressed in A. thaliana, it enhanced the expression of AGSL biosynthetic genes and increased the accumulation of methylsulphinyl GSLs including glucoraphanin significantly (Araki et al. 2013). Therefore, our interest was focused in evaluating the effect of BoMYB29 on AGSL production in B. oleracea. To our knowledge, this is the first study showing a successful overexpression of MYB29 in B. oleracea.

In agreement with our observations in the BoMYB29 DH AG1012 overexpression lines, the BoMYB29 overexpression in myb28myb29 Arabidopsis mutant, the methylsulphinyl GSL content, including glucoraphanin was greatly increased, indicating the suitability of BoMYB29 as a regulator for increasing methylsulphinyl GSL content. (Araki et al. 2013). Unfortunately, the analysis of plants overexpressing BoMYB29 and potential AtMYB29 knock-out mutants was not conclusive as to detect the direct transcriptional targets of AtMYB29 in A. thaliana (Sønderby et al. 2010; Araki et al. 2013).

Our results also demonstrate that BoMYB29 plays a key role in the production of AGSLs in B. oleracea, activating all the genes in the pathway. The BoMYB29 overexpressing lines created for this study displayed a higher expression of the B. oleracea orthologues of A. thaliana genes previously found to be up-regulated by this transcription factor in A. thaliana (Gigolashvili et al. 2008). Our microarray data show the same mode of action for $B$. oleracea. The analysis of the whole AGSL pathway in B. oleracea, allows us to affirm that the $B$. oleracea gene encoding the BILE ACID TRANSPORTER 5 (BoBAT5) is the most important target gene regulated by BoMYB29. The AtBAT5 gene has been identified in $A$. thaliana to encode a plastic transporter involved in the AGSL biosynthesis and to be a target of AtMYB29 (Gigolashvili et al. 2009; Sawada et al. 2009).

On a phenotypic level, the overexpression of BoMYB29 increased the production of aliphatic glucosinolates in both modified B. oleracea genotypes, Winspit and DH AG1012. BoMYB29-DH AG1012 lines showed a higher content of 3-methylsulfinylpropyl GSL (GIB) and 4-methylsulfinylbutyl GSL (GRA) compared to the untransformed (WT) plants. On the other hand, the Winspit overexpressing lines, which have a functional BoAOP2 gene, produced a significantly higher content of 2-propenyl/Allyl (SIN) and But-3-enyl (GNP). Similar studies have been performed in A. thaliana where the overexpression of AtMYB29 increased the levels 
of short and long — chained aliphatic glucosinolates including GIB and GRA (Gigolashvili et al. 2009). This confirms that MYB29 is a key transcription factor, which regulates the production of aliphatic GSLs in B. oleracea plants. The absence of Alkenyl GSLs in the DH AG1012, even when BoMYB29 is overexpressed, can be ascribed to the non-functionality of AOP2, which is the enzyme responsible for the production of Alkenyl GSLs from Methylsulfinylalkyl GSLs. The absence of alkenyl GSLs in the DH AG1012 transgenic lines as well as in the DH AG1012 WT plants is fully in line with the absence of one or more steps in the AGSL biosynthetic pathway in this genotype, blocking the biosynthesis of alkenyl-GSLs. The gene is also not functional in B. oleracea var. italica (Gao et al. 2004), which is part of the ancestry of DH AG1012 (Sparrow et al. 2006). Instead of Alkenyl GSLs, the DH accumulates methylsulphinylalkyl-GSLs, including glucoraphanin, contributing to the anti-cancer properties of B. oleracea (Juge et al. 2007; Chi et al. 2015).

In our assays, a concentration of $1000 \mu \mathrm{g} / \mathrm{mL}$ of DH6 plant extract displayed the highest HT29 cancer cell protective effect against subsequent DNA damage induced by hydrogen peroxide. The cell protection observed in our experiment may be produced by GSL degradation products (ITCs), which have a widely documented chemopreventive activity (Traka and Mithen 2009). DNA damage protective effect might be also produced by the complex mixture of compounds present in the plant extract, including the nonvolatile hydrolysis products of the GSLs identified and a range of phenolic compounds, as it was suggested by Boyd et al. (2006) from observations using watercress (Nasturtium officinale) extracts.

Glucosinolates are also useful in agricultural applications. Glucosinolate profile and content have been assessed in the wild B. oleracea Winspit showing high levels of alkenylGSL, in the leaves which make it particularly interesting for biofumigation applications (Gols et al. 2008; Zuluaga et al. 2015). Our expression analysis contribute to a better understanding of the mechanism that regulates the biofumigation properties of Winspit, suggesting that several genes involved in the GSL pathway play a key role in the biofumigation potential of the wild genotype. The high AGSL production in WIN7 and in the Winspit BoMYB29 overexpressing plants was mainly due to the high presence of the 3-butenyl GSL (gluconapin) and the 2 propenyl/Allyl (sinigrin). These alkenyl-GSLs are produced from the methylsulphinylalkylGSLs by the 2-oxoglutarate-dependent dioxygenase encoded by the $A O P 2$ gene. Therefore, our results suggest that the higher production of sinigrin in the Winspit plants is due mainly to the presence of a functional $A O P 2$ gene, which is regulated by MYB29 in B. oleracea. Therefore, BoAOP 2 gene and the gene encoding $B o M Y B 29$ transcription factors could be targeted in breeding programmes aimed at improving the biofumigation properties in Brassicas.
In conclusion, overexpression of the BoMYB29 gene in $B$. oleracea plants up-regulates the AGSL pathway and increases the production of methylsulphinylalkyl GSLs such as the anti-cancer metabolite, glucoraphanin, or alkenyl glucosinolates including the toxic and pungent sinigrin. This difference largely depends on the presence or absence of a functional $B O A O P 2$ allele in a given genotype. Therefore, the results presented in this study illustrate how the BoMYB29 gene from a wild $B$. oleracea can be used by plant breeders towards improving agricultural practices, by developing $B$. oleracea species with higher allelopathic properties against pathogens and pests. At the same time, increasing the synthesis of this transcription factor in particular genotypes, including those derived from economically important crops, improves anticancer effects and thus beneficial properties of Brassica plants for human health.

Acknowledgements This study was funded by the research program Ecology Regarding Genetically Modified Organisms (ERGO) of the Netherlands Organization of Scientific Research (NWO, project 838.06.091). The authors want to thank Dr. Rieta Gols from Wageningen University for providing Winspit seeds, Mrs Charlotte van Twisk, Irmela Kruse and Kristin Hennig from Wageningen University, Dr. Ascension Martinez Sanchez from the University of Reading for their contributions in HPLC analysis and Dr. Penelope Sparrow from The John Innes Centre for her advice in Brassica transformation and Michele Bandecchi for his contribution in DH AG1012 AOP2 characterization.

Author contributions MGMA conceived, planned the project and supervised the research. MGMA and DLZ designed the experiments, discussed the results and drafted the manuscript. DLZ performed plasmid construction, $B$. oleracea transformation and analysed qPCR gene expression. DLZ, AEEOK and RV performed GSL analysis. NSG analysed microarray data. ARM performed statistical analysis. AK, CW and DLZ carried out comet assay. MGMA, DLZ, GS, AK, NSG, AEEOK contributing in writing and revised the paper. All authors read the manuscript and agree with its content.

Open Access This article is distributed under the terms of the Creative Commons Attribution 4.0 International License (http://creativeco mmons.org/licenses/by/4.0/), which permits unrestricted use, distribution, and reproduction in any medium, provided you give appropriate credit to the original author(s) and the source, provide a link to the Creative Commons license, and indicate if changes were made.

\section{References}

Abdull Razis AF, Arumugam A, Konsue N (2017) Glucosinolates and isothiocyanates: cancer preventive effects. In: Yahia EM (ed) Fruit and vegetable phytochemicals: chemistry and human health, 2nd edn. Wiley, Oxford, pp 199-210

Aires A, Carvalho R, Barbosa MD, Rosa E (2009) Suppressing potato cyst nematode, Globodera rostochiensis, with extracts of Brassicacea plants. Am J Potato Res 86:327-333 
Araki R, Hasumi A, Nishizawa OI, Sasaki K, Kuwahara A, Sawada Y, Totoki Y, Toyoda A, Sakaki Y, Li Y, Saito K, Ogawa T, Hirai MY (2013) Novel bioresources for studies of Brassica oleracea: identification of a kale MYB transcription factor responsible for glucosinolate production. Plant Biotechnol 11:1017-1027

Beekwilder J, van Leeuwen W, van Dam NM, Bertossi M, Grandi V, Mizzi L, Soloviev M, Szabados L, Molthoff JW, Schipper B et al (2008) The impact of the absence of aliphatic glucosinolates on insect herbivory in Arabidopsis. PLoS ONE 3:e2068

Benjamini Y, Hochberg Y (1995) Controlling the false discovery rate: a practical and powerful approach to multiple testing. J R Stat Soc 57:289-300

Benjamini Y, Yekutieli D (2001) The control of the false discovery rate in multiple testing under dependency. Ann Stat 29:1165-1188

Boyd LA, McCann MJ, Hashim Y, Bennett RN, Gill CIR, Rowland IR (2006) Assessment of the anti-genotoxic, anti-proliferative, and anti-metastatic potential of crude watercress extract in human colon cancer cells. Nutr Cancer 55:232-241

Broekgaarden C, Poelman EH, Steenhuis G, Voorrips RE, Dicke M, Vosman B (2008) Responses of Brassica oleracea cultivars to infestation by the aphid Brevicoryne brassicae: an ecological and molecular approach. Plant, Cell Environ 31:1592-1605

Chi X, Zhang R, Shen N, Jin Y, Alina A, Yang S, Lin S (2015) Sulforaphane reduces apoptosis and oncosis along with protecting liver injury-induced ischemic reperfusion by activating the Nrf2/ ARE pathway. Hepatol Int 9:321-329

Cohen E, Ophir I, Shaul YB (1999) Induced differentiation in HT29, a human colon adenocarcinoma cell line. J Cell Sci 112:2657-2666

Collins AR (2004) The comet assay for DNA damage and repair. Mol Biotechnol 26:249

Edgar R, Domrachev M, Lash AE (2002) Gene expression omnibus: NCBI gene expression and hybridization array data repository. Nucleic Acids Res 30:207-210

Gamborg OL, Miller RA, Ojima K (1968) Nutrient requirements of suspension cultures of soybean root cells. Exp Cell Res 50:151-158

Gao M, Li G, Yang B, McCombie WR, Quiros CF (2004) Comparative analysis of a Brassica BAC clone containing several major aliphatic glucosinolate genes with its corresponding Arabidopsis sequence. Genome 47:666-679

Gao MQ, Li GY, Potter D, McCombie WR, Quiros CF (2006) Comparative analysis of methylthioalkylmalate synthase (MAM) gene family and flanking DNA sequences in Brassica oleracea and Arabidopsis thaliana. Plant Cell Rep 25:592-598

Gigolashvili T, Yatusevich R, Berger B, Caroline Müller C, Flugge UI (2007) The R2R3-MYB transcription factor HAG1/MYB28 is a regulator of methionine-derived glucosinolate biosynthesis in Arabidopsis thaliana. Plant J 51:247-261

Gigolashvili T, Engqvist M, Yatusevich R, Müller C, Flugge UI (2008) HAG2/MYB76 and HAG3/MYB29 exert a specific and coordinated control on the regulation of aliphatic glucosinolate biosynthesis in Arabidopsis thaliana. New Phytol 177:627-642

Gigolashvili T, Yatusevich R, Rollwitz I, Humphry M, Gershenzon J, Flugge UI (2009) The plastidic bile acid transporter 5 is required for the biosynthesis of methionine-derived glucosinolates in Arabidopsis thaliana. Plant Cell 21:1813-1829

Gill CI, Haldar S, Porter S, Matthews S, Sullivan S, Coulter J, McGlynn H, Rowland I (2004) The effect of cruciferous and leguminous sprouts on genotoxicity, in vitro and in vivo. Cancer Epidemiol Biomark Prev 13:1199-1205

Gols R, Wagenaar R, Bukovinszky T, van Dam NM, Dicke M, Bullock JM, Harvey JA (2008) Genetic variation in defense chemistry in wild cabbages affects herbivores and their endoparasitoids. Ecology 89:1616-1626

Harvey JA, van Dam NM, Raaijmakers CE, Bullock JM, Gols R (2011) Tri-trophic effects of inter- and intra-population variation in defence chemistry of wild cabbage (Brassica oleracea). Oecologia 166:421-431

Hennig K, Verkerk R, Bonnema G, Dekker M (2012) Pitfalls in the desulphation of glucosinolates in a high-throughput assay. Food Chem 134:2355-2361

Hirai MY, Sugiyama K, Sawada Y, Tohge T, Obayashi T, Suzuki A, Araki R, Sakurai N, Suzuki H, Aoki K, Goda H, Ishizaki Nishizawa O, Shibata D, Saito K (2007) Omics-based identification of Arabidopsis Myb transcription factors regulating aliphatic glucosinolate biosynthesis. PNAS 104:6478-6483

Irizarry RA, Hobbs B, Collin F, Beazer-Barclay YD, Antonellis KJ, Scherf U, Speed TP (2003) Exploration, normalization, and summaries of high density oligonucleotide array probe level data. Biostatistics 4:249-264

Juge N, Mithen RF, Traka M (2007) Molecular basis for chemoprevention by sulforaphane: a comprehensive review. Cell Mol Life Sci 64:1105-1127

Kopsell DA, Kopsell DE (2006) Accumulation and bioavailability of dietary carotenoids in vegetable crops. Trends Plant Sci 11:499-507

Lazo GR, Stein PA, Ludwig RA (1991) A DNA transformation-competent Arabidopsis genomic library in Agrobacterium. Biotechnology 9:963-967

Li GY, Quiros CF (2002) Genetic analysis, expression and molecular characterization of BoGSL-ELONG, a major gene involved in the aliphatic glucosinolate pathway of Brassica species. Genetics 162:1937-1943

Li G, Quiros CF (2003) In planta side-chain glucosinolate modification in Arabidopsis by introduction of dioxygenase Brassica homolog BoGSL-ALK. Theor Appl Genet 106:1116-1121

Li ZS, Liu YM, Fang ZY, Yang LM, Zhuang M, Zhang YY (2014) Variation of sulforaphane levels in broccoli (Brassica oleracea Var. Italica) during flower development and the role of gene Aop2. J Liq Chromatogr Relat Technol 37:1199-1211

Liu S, Liu Y, Yang X, Tong C, Edwards D, Parkin IAP, Zhao M, Ma J, Yu J, Huang S et al (2014) The Brassica oleracea genome reveals the asymmetrical evolution of polyploid genomes. Nat Commun 5:3930

Love CG, Graham NS, Lochlainn ÓS, Bowen HC, May ST, White PJ, Broadley MR, Hammond JP, King GJ (2010) A brassica exon array for whole-transcript gene expression profiling. PLoS ONE 5:e12812

Lysak MA, Koch MA, Pecinka A, Schubert I (2005) Chromosome triplication found across the tribe Brassiceae. Genome Res 15:516-525

Murashige T, Skoog F (1962) A revised medium for rapid growth and bio assays with tobacco tissue cultures. Physiol Plant 15:473-497

Nagaharu U (1935) Genome analysis in Brassica with special reference to the experimental formation of B. napus and peculiar mode of fertilization. Jpn J Bot 7:389-452

Neal C, Fredericks D, Griffiths C, Neale A (2010) The characterisation of AOP2: a gene associated with the biosynthesis of aliphatic glucosinolates in Arabidopsis thaliana. BMC Plant Biol 10:170

Newton E, Bullock JM, Hodgson D (2009) Bottom-up effects of glucosinolate variation on aphid colony dynamics in wild cabbage populations. Ecol Entomol 34:614-623

Pinto S, Rosa E, Santos S (1998) Effect of 2-propenyl glucosinolate and derived isothiocyanate on the activity of the nematodes Globodera rostochiensis (Woll.). Acta Hortic 459:323-328

Rangkadilok N, Nicolas ME, Bennett RN, Premier RR, Eagling DR, Taylor PWJ (2002) Developmental changes of sinigrin and glucoraphanin in three Brassica species (Brassica nigra, Brassica juncea and Brassica oleracea var. italica). Sci Hortic 96:11-26

Sawada Y, Toyooka K, Kuwahara A, Sakata A, Nagano M, Saito K, Hirai MY (2009) Arabidopsis bile acid: sodium symporter family 
protein 5 is involved in methionine-derived glucosinolate biosynthesis. Plant Cell Physiol 50:1579-1586

Seo MS, Jin M, Chun JH, Kim SJ, Park BS, Shon SH, Kim JS (2016) Functional analysis of three BrMYB28 transcription factors controlling the biosynthesis of glucosinolates in Brassica rapa. Plant Mol Biol 90:503-516

Singh N, McCoy M, Tice R, Schneider E (1988) A simple technique for quantitation of low levels of DNA damage in individual cells. Exp Cell Res 175:184-191

Sønderby IE, Hansen BG, Bjarnholt N, Ticconi C, Halkier BA, Kliebenstein DJ (2007) A systems biology approach identifies a R2R3 MYB gene subfamily with distinct and overlapping functions in regulation of aliphatic glucosinolates. PLoS ONE 2:e1322

Sønderby IE, Burow M, Rowe HC, Kliebenstein DJ, Halkier BA (2010) A complex interplay of three R2R3 MYB transcription factors determines the profile of aliphatic glucosinolates in Arabidopsis. Plant Physiol 153:348-363

Sparrow PAC, Dale PJ, Irwin JA (2006) Brassica oleracea. In: Kan W (ed) Methods in molecular biology, agrobacterium protocols, 2nd edn. Humana Press Inc, Totowa, pp 417-426

Su X, Jiang X, Meng L, Dong X, Shen Y, Xin Y (2018) Anticancer activity of sulforaphane: the epigenetic mechanisms and the Nrf2 signaling pathway. Oxidative Med Cell Longev 2018:5438179

Tiznado-Hernández ME, Troncoso-Rojas R (2006) Control of fungal diseases with isothiocyanates. Stewart Postharvest Rev 2:1-14

Traka M, Mithen R (2009) Glucosinolates, isothiocyanates and human health. Phytochem 8:269-282

Wang H, Wu J, Sun S, Liu B, Cheng F, Sun R, Wang X (2011) Glucosinolate biosynthetic genes in Brassica rapa. Gene 487:135-142
Yi GE, Robin AH, Yang K, Park JI, Kang JG, Yang TJ, Nou IS (2015) Identification and expression analysis of glucosinolate biosynthetic genes and estimation of glucosinolate contents in edible organs of Brassica oleracea subspecies. Molecules 20:13089-13111

Yin L, Chen H, Cao B, Lei J, Chen G (2017) Molecular characterization of MYB28 involved in aliphatic glucosinolate biosynthesis in Chinese Kale (Brassica oleracea var. alboglabra Bailey). Front Plant Sci 8:1083

Zang YX, Kim HU, Kim JA, Lim MH, Jin M, Lee SC, Kwon SJ, Lee SI, Hong JK, Park TH, Mun JH, Seol YJ, Hong SB, Park BS (2009) Genome-wide identification of glucosinolate synthesis genes in Brassica rapa. FEBS J 276:3559-3574

Zhang J, Liu Z, Liang J, Wu J, Cheng F, Wang X (2015) Three genes encoding AOP2, a protein involved in aliphatic glucosinolate biosynthesis, are differentially expressed in Brassica rapa. J Exp Bot 66:6205-6218

Zuluaga DL, van Ommen Kloeke AEE, Verkerk R, Röling WFM, Ellers J, Roelofs D, Aarts MGM (2015) Biofumigation using a wild Brassica oleracea accession with high glucosinolate content affects beneficial soil invertebrates. Plant Soil 394:155-163

Publisher's Note Springer Nature remains neutral with regard to jurisdictional claims in published maps and institutional affiliations.

\section{Affiliations}

\section{Diana L. Zuluaga ${ }^{1,7}$ (1) Neil S. Graham ${ }^{2} \cdot$ Annett Klinder $^{3} \cdot$ A. E. Elaine van Ommen Kloeke ${ }^{4}$ Angelo R. Marcotrigiano ${ }^{5}$. Carol Wagstaff $^{3} \cdot$ Ruud Verkerk $^{6} \cdot$ Gabriella Sonnante $^{7} \cdot$ Mark G. M. Aarts $^{1}$}

Neil S. Graham

Neil.Graham@nottingham.ac.uk

Annett Klinder

A.Klinder@gmx.de

A. E. Elaine van Ommen Kloeke elainevok@gmail.com

Angelo R. Marcotrigiano

angelo.marcotrigiano@uniba.it

Carol Wagstaff

c.wagstaff@reading.ac.uk

Ruud Verkerk

ruud.verkerk@wur.nl

Gabriella Sonnante

gabriella.sonnante@ibbr.cnr.it

Mark G. M. Aarts

mark.aarts@wur.nl
1 Laboratory of Genetics, Wageningen University, Droevendaalsesteeg 1, 6708 PB Wageningen, The Netherlands

2 Plant and Crop Sciences Division, School of Biosciences, University of Nottingham, Sutton Bonington Campus, Loughborough LE12 5RD, Leicestershire, UK

3 Department of Food and Nutritional Sciences, University of Reading, PO Box 226, Whiteknights, Reading RG6 6AP, $\mathrm{UK}$

4 Department of Ecological Science, Faculty of Earth and Life Sciences, VU University Amsterdam, De Boelelaan 1085, 1081 HV Amsterdam, The Netherlands

5 Department of Soil, Plant and Food Science, University of Bari "Aldo Moro", Bari, Italy

6 Food Quality and Design, Wageningen University, P.O. Box 17, 6700AA Wageningen, The Netherlands

7 Institute of Biosciences and Bioresources, National Research Council, Via G. Amendola 165/A, 70126 Bari, Italy 